\title{
Surface blistering and deuterium retention in tungsten exposed to low-energy deuterium plasma at different temperatures
}

\author{
Shaoyang Qin ${ }^{1,2}$, Jinliang Wang $^{1}$, Liang Gao ${ }^{3}$, Long Cheng ${ }^{1,2}$, Yue Yuan ${ }^{1,2,}$, Wolfgang Jacob ${ }^{3}$, \\ Guang-Hong $\mathrm{Lu}^{1,2}$ \\ ${ }^{1}$ School of Physics \& Nuclear Energy Engineering, Beihang University, Beijing, 100191, China \\ ${ }^{2}$ Beijing Key Laboratory of Advanced Nuclear Materials and Physics, Beihang University, Beijing, \\ 100191, China \\ ${ }^{3}$ Max-Planck-Institut für Plasmaphysik, Boltzmannstraße 2, D-85748 Garching, Germany
}

\begin{abstract}
Surface morphology and deuterium retention in tungsten have been examined after exposure to a low-energy deuterium plasma with an ion fluence of $6.0 \times 10^{24} \mathrm{D} / \mathrm{m}^{2}$ at various temperatures. Optical differential interference contrast microscope and scanning electron microscope equipped with focused ion beam were applied for surface observations. D $\left({ }^{3} \mathrm{He}, \mathrm{p}\right)$ ${ }^{4} \mathrm{He}$ nuclear reaction at ${ }^{3} \mathrm{He}$ energies varying from 0.5 to $4.5 \mathrm{MeV}$ was used to determine the deuterium depth distributions within the depth of $8.0 \mu \mathrm{m}$. The thermal desorption spectroscopy was applied for deuterium retention measurement. The observed surface blistering and deuterium retention are found to strongly depend on the exposure temperature. At $230 \mathrm{~K}$, many small blisters are formed on the tungsten surface. As the exposure temperature increases to $370 \mathrm{~K}$, the blisters become sparser and larger. At $520 \mathrm{~K}$ no blisters appear. The deuterium retention is $1.4 \times 10^{20} \mathrm{D} / \mathrm{m}^{2}$ at $230 \mathrm{~K}$. Then it increases to $1.1 \times 10^{21} \mathrm{D} / \mathrm{m}^{2}$ as the exposure temperature rises to $370 \mathrm{~K}$, and decreases to $2.3 \times 10^{20} \mathrm{D} / \mathrm{m}^{2}$ at $520 \mathrm{~K}$.
\end{abstract}

Keywords: tungsten, surface blistering, deuterium retention, temperature dependence
Published in:
Nuclear Instruments and Methods B 450 (2019) 210-214.
doi:
10.1016/j.nimb.2018.04.012
Submitted:
29.10.2017
Accepted:
09.04 .2018
Available online: 18.04 .2018 


\section{Introduction}

Tungsten is a candidate material for plasma-facing materials in future fusion devices [1], because it exhibits high melting point and thermal conductivity as well as the low erosion rate Tungsten in future fusion devices will be exposed to intense fluxes of energetic hydrogen isotopes, helium and neutron [2]. Experiments have shown that tungsten is prone to be blistering under deuterium implantation [3-5]. The implantation process also leads to the concern about deuterium inventories in tungsten[6]. Previous investigations demonstrated that a dependence of the blister formation and deuterium retention on particle fluence, irradiation duration, tungsten surface properties and exposure temperature [7-9]. The studies about the influence of temperature were mainly carried out at 300-900K [9-11] and the results differ from each other due to different plasma devices and different sample types [12,13]. Although Ref [14] has reported the blistering morphology of $\mathrm{W}$ samples exposed at $230 \mathrm{~K}$, the D retention profile is not provided in that work. The main objective of the present work is to study the temperature dependence of surface blistering and deuterium retention in tungsten after exposure to deuterium plasma $\left(\geqslant 10^{20}\right.$ ions $\left./ \mathrm{m}^{2} \cdot \mathrm{s}\right)$ at different temperatures including the lower values. We investigate the deuterium behaviour in tungsten after exposures at $230 \mathrm{~K}$, $370 \mathrm{~K}$ and $520 \mathrm{~K}$ for more than $16 \mathrm{~h}$. We are focusing on the influence of temperature while keeping other experimental conditions the same for all the exposures. Surface modification will be described, and the deuterium depth profiles will also be discussed in attempt to further understand the connection between the observed blistering features and the D retention behaviour.

\section{Experiment}

Tungsten samples with dimensions of $12 \times 15 \times 0.8 \mathrm{~mm}^{3}$ were cut from a hot-rolled sheet (PLANSEE, 99.97\% purity). They were mechanically polished until the surface was mirror-like. Subsequently they were annealed in vacuum $\left(<10^{-6} \mathrm{~Pa}\right)$ for $2 \mathrm{~h}$ at $1200 \mathrm{~K}$ for hydrogen degassing, surface stress release and oxide layer removal. The polished surface of initial $\mathrm{W}$ sample after annealing is shown in Fig.1.The grains are visible, and the average grain size is about $6 \mu \mathrm{m}$.

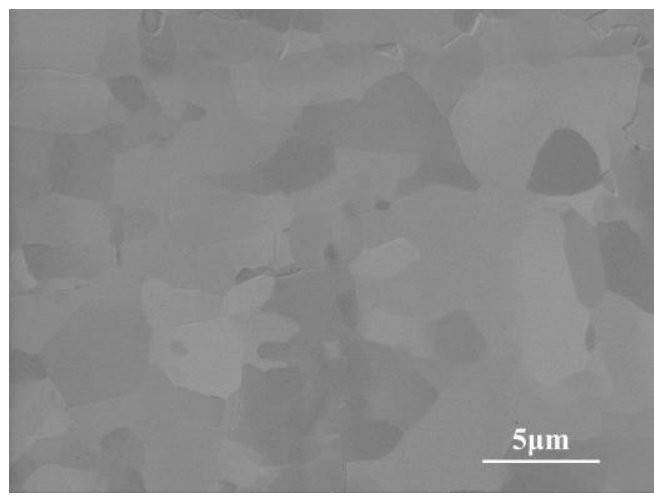

Fig.1. Polished surface of initial W samples after annealing 
Deuterium plasma implantation were performed in a low-pressure steady-state electron cyclotron resonance (ECR) plasma chamber 'PlaQ' [15]. To generate a deuterium plasma, $\mathrm{D}_{2}$ gas was filled in the plasma generation section to a pressure of $1.0 \mathrm{~Pa}$. The deuterium ion flux consisted predominantly of $\mathrm{D}_{3}{ }^{+}$ions $(94 \%)$ with minor contributions of $\mathrm{D}_{2}{ }^{+}(3 \%)$ and $\mathrm{D}^{+}(3 \%)$ [16]. The samples were exposed to deuterium plasma for $16 \mathrm{~h} 47 \mathrm{~min}$ with a fluence of $6.0 \times 10^{24} \mathrm{D} / \mathrm{m}^{2}$ at 230,370 and $520 \mathrm{~K}$. A bias voltage of $-200 \mathrm{~V}$ DC was applied for all implantations. Together with the plasma potential of $15 \mathrm{eV}$ this yields ion energy of $215 \mathrm{eV}$. For the dominant ion species $\mathrm{D}_{3}{ }^{+}$this corresponds to ion energy of $72 \mathrm{eV}$ per $\mathrm{D}$ atom. But for the small fraction of $\mathrm{D}^{+}$ions the maximum ion energy is $215 \mathrm{eV}$. We used two open circuit thermostats one with silicon oil and the other ethanol to control the sample holder temperature between 230 and $520 \mathrm{~K}$.

The surface modifications were analysed by an optical differential interference contrast (DIC) microscope (Olympus LEXT OLS4000) and a scanning electron microscope (SEM, MIRA3 TESCAN). The sub-surface morphology was observed after cross-sectioning by a focused ion beam (TESCAN LYRA3 FEG-SEM/FIB). To reduce artefacts due to the FIB cutting process, a Pt film was deposited onto the investigated surface in-situ prior to the cross-sectioning. The deuterium concentration profile in the tungsten samples was measured by nuclear reaction analysis using $\mathrm{D}\left({ }^{3} \mathrm{He}, \mathrm{p}\right){ }^{4} \mathrm{He}$ reaction. To determine the deuterium concentration profile up to greater depths, an analysing beam of ${ }^{3} \mathrm{He}$ ions with energies varying from 0.5 to 4.5 $\mathrm{MeV}$ was used, which allows us to determine the retained D concentration up to a depth of $8 \mu \mathrm{m}$. The $\mathrm{D}$ depth profiles up to the maximum analysis depth of about $8 \mu \mathrm{m}$ were determined by deconvolving the acquired proton spectra from the ${ }^{3} \mathrm{He}$ NRA measurements using the NRADC data evaluation program [17].

$\mathrm{D}$ desorption from the irradiated $\mathrm{W}$ were analysed by thermal desorption spectroscopy (TDS). The $\mathrm{W}$ targets were heated up to $1273 \mathrm{~K}$ with a ramping rate of $1 \mathrm{~K} / \mathrm{s}$. The gases such as $\mathrm{D}_{2}$ (mass 4), HD (mass 3) were monitored by a quadrupole mass spectrometer (MKS microVision). For calculating the total $\mathrm{D}$ retention, $\mathrm{HD}$ and $\mathrm{D}_{2}$ were taken into account.

\section{Results}

\subsection{Surface morphology}

Optical DIC micrographs of the $\mathrm{W}$ targets are shown in Fig.2. The initial $\mathrm{W}$ sample is shown in Fig.2(a). After exposure to a fluence of $6.0 \times 10^{24} \mathrm{D} / \mathrm{m}^{2}$ at $230 \mathrm{~K}$, we can see many dome-shaped blisters on the surface which are indicated by the red arrows (Fig.2(b)). We measured the size of the blisters. The size is mainly in the range of 0.2-3.6 $\mu \mathrm{m}$ and the average size is $1.4 \mu \mathrm{m}$. The blisters are irregularly distributed and seem to appear in groups. If the temperature is increased to $370 \mathrm{~K}$, the small blisters disappear, whereas some large blisters with size $>20 \mu \mathrm{m}$ appear (Fig.2(c)). In addition, we can find that in some cases small blisters are formed on top of large blisters. The sample exposed to deuterium at $520 \mathrm{~K}$ is shown in Fig.2(d). No blisters are formed on the surface, which is similar as the initial sample without exposure. 


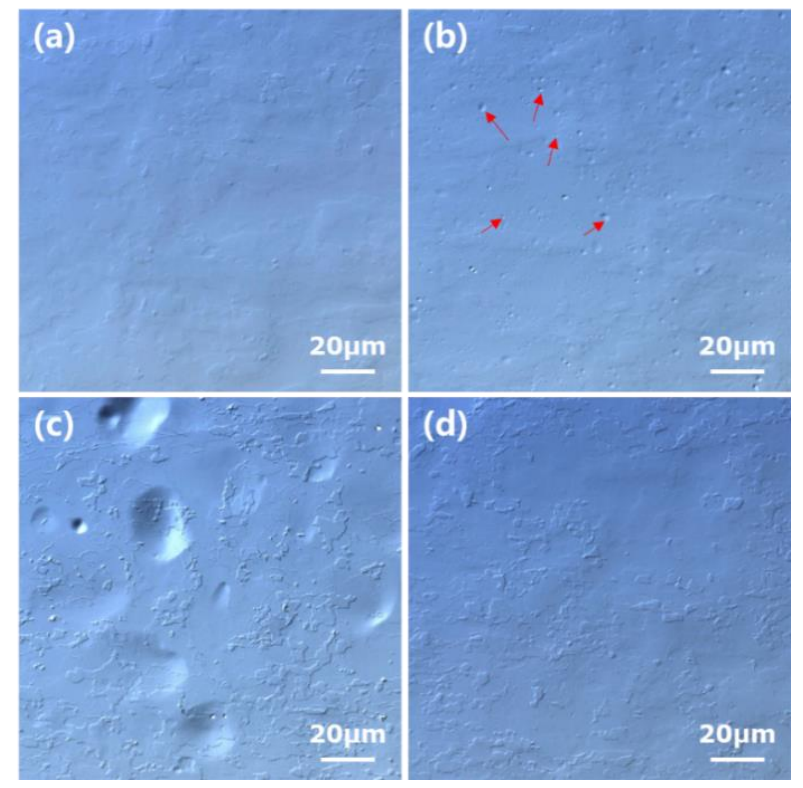

Fig.2. Optical DIC micrographs of initial tungsten sample without exposure (a), with D exposure at $230 \mathrm{~K}$ (b), 370 $\mathrm{K}(\mathrm{c})$ and $520 \mathrm{~K}(\mathrm{~d})$.

\subsection{Sub-surface morphology}

Fig.3(a)(c) shows the sub-surface morphology of a small blister with a diameter of $2.0 \mu \mathrm{m}$ on the sample exposed to deuterium plasma at $230 \mathrm{~K}$. From the picture we can see a narrow cavity which is indicated by the red rectangle in Fig.3(c). This cavity is along a sub-surface grain boundary. The width of this cavity is about $1 \mu \mathrm{m}$ and the distance to the top surface is $300 \mathrm{~nm}$. At the exposure temperature of $370 \mathrm{~K}$, the blister size is much larger, and we select a blister with a diameter of about $20 \mu \mathrm{m}$ as shown in Fig.3(b). We can see two main cavities under this blister in Fig.3(d). They are both in grain boundaries and extend over several grains. The larger one is located at a depth of $1.4 \mu \mathrm{m}$ and the smaller one is in a depth up about 3.4 $\mu \mathrm{m}$.

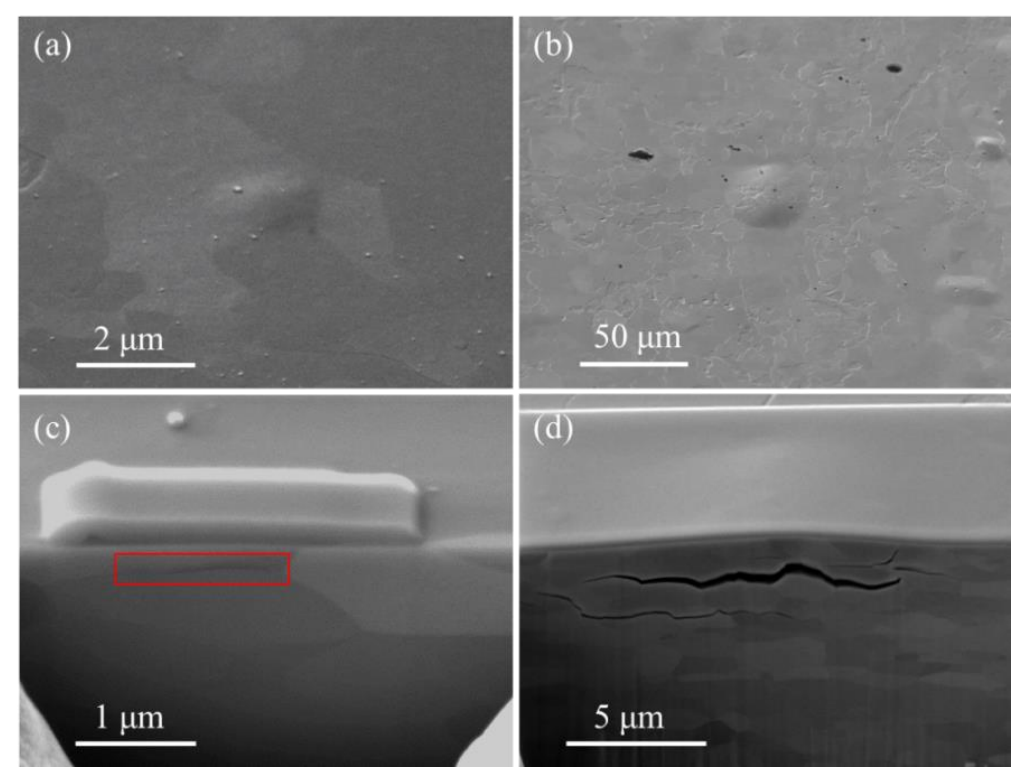

Fig.3. SEM images of cross-sections of tungsten samples exposed to low energy deuterium exposure with ion fluences of $6.0 \times 10^{24} \mathrm{D} / \mathrm{m}^{2}$ at $230 \mathrm{~K}(\mathrm{a})(\mathrm{c})$ and $370 \mathrm{~K}(\mathrm{~b})(\mathrm{d})$. 


\subsection{Deuterium depth profiles}

Figure 3 shows the deuterium depth distribution which is determined using NRADC for the de-convolution of the acquired proton spectra. For these three samples, the deuterium concentration reaches the maximum of $\sim 1 \%$ at the top surface. It should be noted that, this concentration in this D-oversaturated layer in top-most surface is actually the averaged value by NRADC for the best depth resolution with the present NRA setup. More details can be find in Ref. [18]. At $230 \mathrm{~K}$, the deuterium concentration decreases to $0.3 \%$ in the depth interval up to $127 \mathrm{~nm}$ and it drops sharply to $1.8 \times 10^{-5}$ in depths larger than $\sim 2 \mu \mathrm{m}$. At $370 \mathrm{~K}$, the concentration of deuterium decreases to $0.5 \%$ in the depth of $32 \mathrm{~nm}$. When the depth goes to $317 \mathrm{~nm}$ it decreases to $0.15 \%$. For depths larger than $2.8 \mu \mathrm{m}$ it increases slightly to $0.39 \%$ and then drops again to $0.28 \%$ for depths larger than $4.0 \mu \mathrm{m}$. This high deuterium concentration could be due to accumulation of $\mathrm{D}_{2}$ molecules in cavities created during the exposure. Finally, for depths larger than $7 \mu \mathrm{m}$ the deuterium concentration is still $0.11 \%$ which is much higher than for the other two samples. At $520 \mathrm{~K}$, most of the retained deuterium is detectable only within the $33 \mathrm{~nm}$ thick top layer. Beyond $33 \mathrm{~nm}$, the deuterium concentration decreases to $1.5 \times 10^{-5}$. Similar phenomenon is also observed in [19].

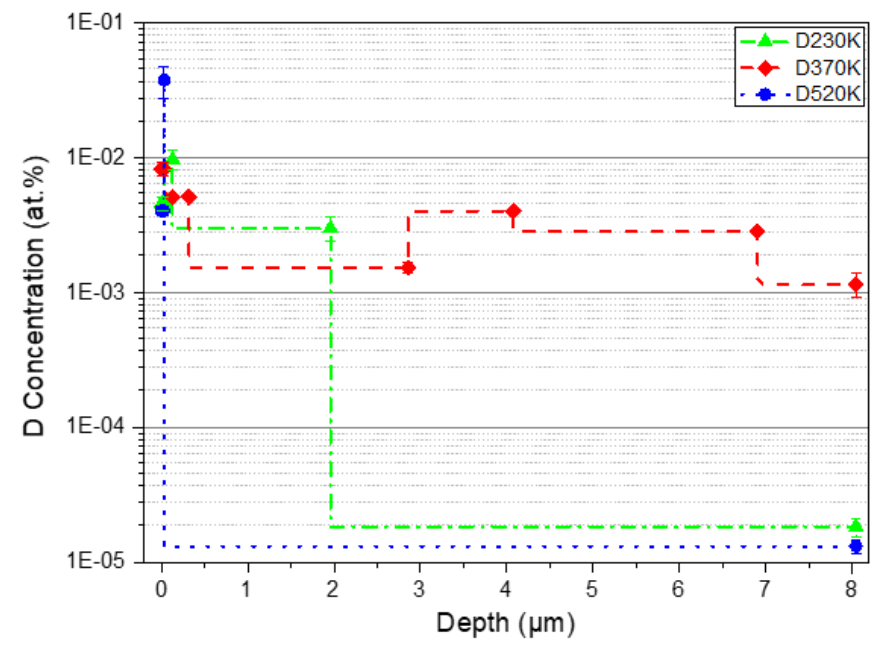

Fig.4. Deuterium depth profiles in tungsten after deuterium implantation with a fluence of $6 \times 10^{24} \mathrm{D} / \mathrm{m}^{2}$ at different temperatures.

\subsection{Deuterium total retention}

The $\mathrm{D}_{2}$ desorption spectra for the $\mathrm{W}$ samples exposed to $\mathrm{D}$ plasma at different temperatures are shown in Fig.5. The sample exposed to D plasma at $230 \mathrm{~K}$ shows a desorption peak at about $460 \mathrm{~K}$. The sample exposed at $370 \mathrm{~K}$ shows two peaks. A dominant desorption peak is located at about $550 \mathrm{~K}$ and the other shoulder peak is located at lower temperature about $450 \mathrm{~K}$. The sample exposed at $520 \mathrm{~K}$ has only one peak at about $560 \mathrm{~K}$.

We can classify the desorption peaks into two types: the low temperature peak, 450-460 K, and the high temperature peak, 550-560 K. According to reaction-diffusion models [20], temperature influences the rate coefficients for D diffusion and detrapping. As indicated by the D depth profile (Fig. 4), D diffusion in W is very low at $230 \mathrm{~K}$. Therefore, this sample just has a low temperature desorption peak. 
For $520 \mathrm{~K}$ exposure, the desorption peak is not symmetric, and it extends to $700 \mathrm{~K}$. It indicates that the inward diffusion at this temperature is significant. However, at $520 \mathrm{~K}$ the detrapping rate is also high. The trapped D in the near surface can be easily detrapped and releases out of the sample or diffuse inward bulk. Hence, there is only a high temperature desorption peak.

For the medium exposure temperature $370 \mathrm{~K}$, we can find two strong desorption peaks in Fig.5. Combined with the depth profiles, it is suggested that at $370 \mathrm{~K} \mathrm{D}$ diffusion is stronger than at $230 \mathrm{~K}$ and detrapping is weaker than at $520 \mathrm{~K}$.

The total $\mathrm{D}$ retention, considering contributions from both $\mathrm{D}_{2}$ and HD is shown in the Fig.6. The $\mathrm{D}$ retention in sample exposed at $370 \mathrm{~K}$ shows an amount about $1.1 \times 10^{21} \mathrm{D} / \mathrm{m}^{2}$. The $\mathrm{D}$ retention in the samples exposed at $230 \mathrm{~K}$ and $520 \mathrm{~K}$ are $1.4 \times 10^{20} \mathrm{D} / \mathrm{m}^{2}$ and $2.3 \times 10^{20} \mathrm{D} / \mathrm{m}^{2}$ respectively. They are much lower than that at $370 \mathrm{~K}$.

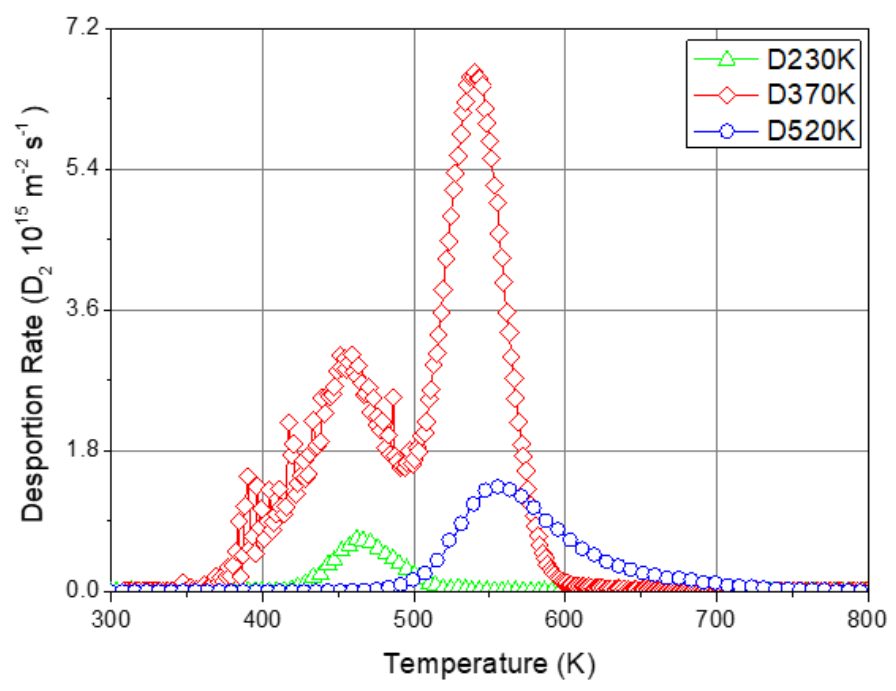

Fig.5. $\mathrm{D}_{2}$ desorption profiles for $\mathrm{W}$ samples irradiated at different temperatures.

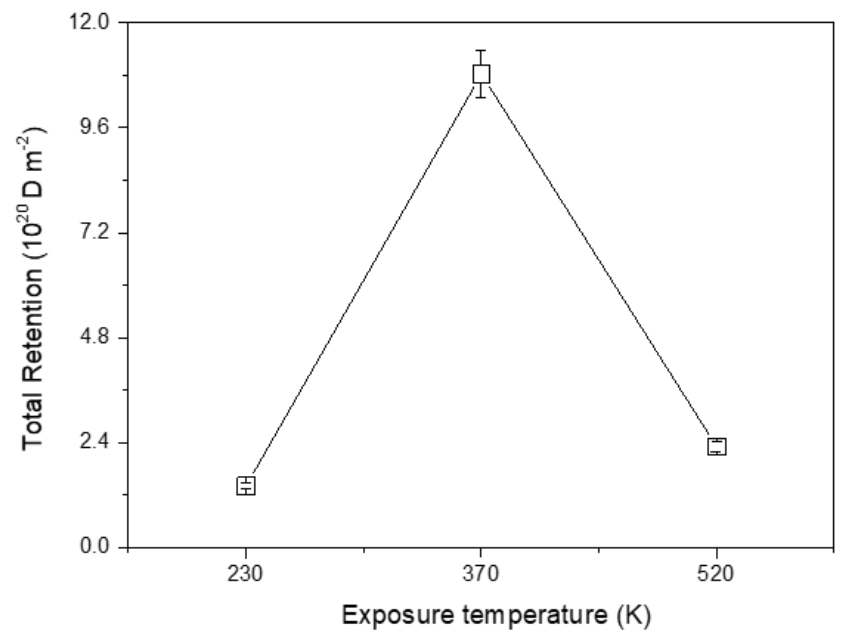

Fig.6. Total amount of D retained in W samples irradiated at different temperatures. 


\section{Discussion}

From what has been shown above, it is clear that the exposure temperature has a great impact on the surface blistering and deuterium retention. After exposure to low-energy deuterium plasma at $230 \mathrm{~K}$ and $370 \mathrm{~K}$, many blisters were formed on the samples surface. Besides, cavities were observed underneath the blisters. Fig.3(a) shows that the cavity is in a depth of $300 \mathrm{~nm}$ and the blister diameter is $2.0 \mu \mathrm{m}$. Fig.3(b) shows that the cavities is located at 3.4 $\mu \mathrm{m}$ deep and the blister size is $20 \mu \mathrm{m}$. At the same time, one can find that the deuterium concentration in this depth range is relatively high as shown in Fig.4. The mechanism of plastic deformation due to deuterium supersaturation [21] may be responsible for the blister formation and growth [22,23]. The solution of deuterium in tungsten is very low. During plasma irradiation, deuterium concentration in the implantation zone greatly exceeds the solubility limit. The deuterium in tungsten will stress the matrix lattice until plastic deformation occurs to alleviate the stress. This deformation is assumed to be due to the generation of vacancies, vacancy complexes and microscopic cavities at depths of several micrometres [24]. With more and more deuterium atoms diffusing into the cavities, they can recombine on the cavity surfaces. When the pressure of the $\mathrm{D}_{2}$ gas inside these cavities exceeds the toughness of the material, the stress can be relaxed by dislocations moving along lattice planes through the whole crystallite leading to the cavities at the grain boundaries [25]. This corresponds to the cavities which follow the sub-surface grain boundaries in Fig.3. It can also be responsible for the blister formation.

We find that the size of the blisters with D $370 \mathrm{~K}$ exposure are larger than that with D $230 \mathrm{~K}$ exposure and at the same time the cavities are larger and deeper. According to Shu [26] the deuterium in vacancy can form the deuterium-vacancy clusters and they can diffuse deeply into the bulk. From the NRA results we know that the deuterium concentration at $370 \mathrm{~K}$ is high in the bulk especially in the depth beyond $2.8 \mu \mathrm{m}$. It indicates that temperature can promote the deuterium or deuterium-vacancy clusters diffusing into the deeper area. Consequently, the cavities are located deeper, and the sizes are larger than at $230 \mathrm{~K}$. As discussed in section 3.4, the TDS spectra also shows that temperature could enhance the ability of $\mathrm{D}$ diffusion in W. It corresponds with the NRA data.

At $520 \mathrm{~K}$ we do not find blisters on the surface and the deuterium retention is also very little. Roszell et al. have studied the temperature dependence of deuterium retention mechanisms in tungsten [9,27]. It is said that different trapping mechanisms occur at about $450 \mathrm{~K}$. If the temperature is lower than $450 \mathrm{~K}$, the implanted deuterium could just be trapped in low energy trap site. With the temperature increases, the high energy trap site would be created. Therefore, the deuterium diffusion process is also very different with varying temperature. That may be responsible for our $520 \mathrm{~K}$ consequence. But in Roszell's study, the implanted ion energy is much higher than ours and the ion fluence is much lower. It is not easy to interpret the absence of blistering and deuterium inventories in $\mathrm{W}$ sample after D loading at $520 \mathrm{~K}$. A corresponding check of this issue is planned for the future.

\section{Conclusion}

In the present experiments, significant temperature dependence of surface morphology and deuterium retention is found for tungsten exposed to low-energy deuterium plasma for $>16 \mathrm{~h}$ 
with ion fluences of $6.0 \times 10^{24} \mathrm{D} / \mathrm{m}^{2}$. At $230 \mathrm{~K}$, many small blisters with diameters of 0.2-3.6 $\mu \mathrm{m}$ are formed on the tungsten surface, and fine cracks are observed in the sub-surface along grain boundaries. In this case, the deuterium concentration has the maximum of $\sim 1 \%$ in the near-surface of $127 \mathrm{~nm}$ and in the sub-surface layer (at depths from $127 \mathrm{~nm}$ to $2 \mu \mathrm{m}$ ), it decreases to $0.3 \%$. The $\mathrm{D}$ retention at this temperature is about $1.4 \times 10^{20} \mathrm{D} / \mathrm{m}^{2}$ and the desorption peak is located at about $460 \mathrm{~K}$. As the exposure temperature increases, the blisters become sparser and larger. The average size is $20 \mu \mathrm{m}$, and large cavities with a volume of tens micrometres are found along the grain boundaries. As this takes place, the average deuterium concentration in bulk with depth of $8 \mu \mathrm{m}$ is above $0.1 \%$. The D retention increases to $1.1 \times 10^{21} \mathrm{D} / \mathrm{m}^{2}$ and it has two desorption peaks at about $450 \mathrm{~K}$ and $550 \mathrm{~K}$. No blisters appear at $520 \mathrm{~K}$, and the deuterium concentration in the bulk is very low. The total retention of $\mathrm{D}$ is $2.3 \times 10^{20} \mathrm{D} / \mathrm{m}^{2}$ and the desorption peak is located at about $560 \mathrm{~K}$.

\section{Acknowledgments}

Part of this work was supported by the National Nature Science Foundation of China under contract No. 11775015. Shaoyang Qin is grateful to funding by Beihang University which financed the research visit at IPP for 3 months.

\section{References}

[1] V. Philipps, Tungsten as material for plasma-facing components in fusion devices, Journal of Nuclear Materials. 415 (2011) S2-S9.

[2] M. Merola, D. Loesser, A. Martin, P. Chappuis, R. Mitteau, V. Komarov, R.A. Pitts, S. Gicquel, V. Barabash, L. Giancarli, J. Palmer, M. Nakahira, A. Loarte, D. Campbell, R. Eaton, A. Kukushkin, M. Sugihara, F. Zhang, C.S. Kim, R. Raffray, L. Ferrand, D. Yao, S. Sadakov, A. Furmanek, V. Rozov, T. Hirai, F. Escourbiac, T. Jokinen, B. Calcagno, S. Mori, ITER plasma-facing components, Fusion Engineering and Design. 85 (2010) 2312-2322.

[3] L. Buzi, G. De Temmerman, B. Unterberg, M. Reinhart, A. Litnovsky, V. Philipps, G. Van Oost, S. Möller, Influence of particle flux density and temperature on surface modifications of tungsten and deuterium retention, Journal of Nuclear Materials. 455 (2014) 316-319.

[4] M. Balden, S. Lindig, A. Manhard, J.-H. You, D2 gas-filled blisters on deuterium-bombarded tungsten, Journal of Nuclear Materials. 414 (2011) 69-72.

[5] A. Manhard, K. Schmid, M. Balden, W. Jacob, Influence of the microstructure on the deuterium retention in tungsten, Journal of Nuclear Materials. 415 (2011) S632-S635.

[6] M.H.J. 't Hoen, M. Balden, A. Manhard, M. Mayer, S. Elgeti, A.W. Kleyn, P.A. Zeijlmans van Emmichoven, Surface morphology and deuterium retention of tungsten after low- and high-flux deuterium plasma exposure, Nuclear Fusion. 54 (2014) 83014.

[7] W.M. Shu, A. Kawasuso, Y. Miwa, E. Wakai, G.-N. Luo, T. Yamanishi, Microstructure dependence of deuterium retention and blistering in the near-surface region of tungsten exposed to high flux deuterium plasmas of $38 \mathrm{eV}$ at $315 \mathrm{~K}$, Physica Scripta. T128 (2007) 96-99.

[8] G.N. Luo, W.M. Shu, M. Nishi, Incident energy dependence of blistering at tungsten irradiated by low energy high flux deuterium plasma beams, Journal of Nuclear Materials. 347 (2005) 111-117.

[9] V.K. Alimov, B. Tyburska-Püschel, S. Lindig, Y. Hatano, M. Balden, J. Roth, K. Isobe, M. Matsuyama, T. Yamanishi, Temperature dependence of surface morphology and deuterium retention in polycrystalline ITER-grade tungsten exposed to low-energy, high-flux D plasma, Journal of Nuclear Materials. 420 (2012) 519-524. 
[10] L. Buzi, G. De Temmerman, B. Unterberg, M. Reinhart, A. Litnovsky, V. Philipps, G. Van Oost, S. Möller, Influence of particle flux density and temperature on surface modifications of tungsten and deuterium retention, Journal of Nuclear Materials. 455 (2014) 316-319.

[11] M.Y. Ye, H. Kanehara, S. Fukuta, N. Ohno, S. Takamura, Blister formation on tungsten surface under low energy and high flux hydrogen plasma irradiation in NAGDIS-I, in: Journal of Nuclear Materials, North-Holland, 2003: pp. 72-76.

[12] K. Tokunaga, M.J. Baldwin, R.P. Doerner, N. Noda, Y. Kubota, N. Yoshida, T. Sogabe, T. Kato, B. Schedler, Blister formation and deuterium retention on tungsten exposed to low energy and high flux deuterium plasma, in: Journal of Nuclear Materials, 2005: pp. 887-891.

[13] M. Balden, A. Manhard, S. Elgeti, Deuterium retention and morphological modifications of the surface in five grades of tungsten after deuterium plasma exposure, Journal of Nuclear Materials. 452 (2014) 248 256.

[14] L. Gao, U. von Toussaint, W. Jacob, M. Balden, A. Manhard, Suppression of hydrogen-induced blistering of tungsten by pre-irradiation at low temperature, Nuclear Fusion. 54 (2014) 122003.

[15] a Manhard, T. Schwarz-Selinger, W. Jacob, Quantification of the deuterium ion fluxes from a plasma source, Plasma Sources Science and Technology. 20 (2011) 15010.

[16] L. Gao, W. Jacob, T. Schwarz-Selinger, A. Manhard, Deuterium implantation into tungsten nitride: Negligible diffusion at 300 K, Journal of Nuclear Materials. 451 (2014) 352-355.

[17] K. Schmid, U. von Toussaint, Statistically sound evaluation of trace element depth profiles by ion beam analysis, Nuclear Instruments and Methods in Physics Research Section B: Beam Interactions with Materials and Atoms. 281 (2012) 64-71.

[18] L. Gao, W. Jacob, U. von Toussaint, A. Manhard, M. Balden, K. Schmid, T. Schwarz-Selinger, Deuterium supersaturation in low-energy plasma-loaded tungsten surfaces, Nuclear Fusion. 57 (2017) 16026.

[19] L. Gao, W. Jacob, P. Wang, U. von Toussaint, A. Manhard, Influence of nitrogen pre-implantation on deuterium retention in tungsten, Physica Scripta. T159 (2014) 14023.

[20] P. Franzen, C. Garcia-Rosales, H. Plank, V.K. Alimov, Hydrogen trapping in and release from tungsten: Modeling and comparison with graphite with regard to its use as fusion reactor material, Journal of Nuclear Mated. als (1997) 241-243.

[21] J.B. Condon, T. Schober, Hydrogen bubbles in metals, Journal of Nuclear Materials. 207 (1993) 1-24.

[22] A.A. Haasz, M. Poon, J.W. Davis, Effect of ion damage on deuterium trapping in tungsten, Journal of Nuclear Materials. 266 (1999) 520-525.

[23] V.K. Alimov, J. Roth, M. Mayer, Depth distribution of deuterium in single- and polycrystalline tungsten up to depths of several micrometers, Journal of Nuclear Materials. 337-339 (2005) 619-623.

[24] V.K. Alimov, W.M. Shu, J. Roth, S. Lindig, M. Balden, K. Isobe, T. Yamanishi, Temperature dependence of surface topography and deuterium retention in tungsten exposed to low-energy, high-flux D plasma, Journal of Nuclear Materials. 417 (2011) 572-575.

[25] P. Gumbsch, Controlling Factors for the Brittle-to-Ductile Transition in Tungsten Single Crystals, Science. 282 (1998) 1293-1295.

[26] W.M. Shu, M. Nakamichi, V.K. Alimov, G.N. Luo, K. Isobe, T. Yamanishi, Deuterium retention, blistering and local melting at tungsten exposed to high-fluence deuterium plasma, Journal of Nuclear Materials. 390-391 (2009) 1017-1021.

[27] J.P. Roszell, J.W. Davis, A.A. Haasz, Temperature dependence of deuterium retention mechanisms in tungsten, Journal of Nuclear Materials. 429 (2012) 48-54. 